\title{
The Gravity of Cryptocurrency and Prospects in a Post-Pandemic Economy
}

\author{
George Abuselidze ${ }^{1 *}$, and Gia Zoidze ${ }^{2}$ \\ ${ }^{1}$ Batumi Shota Rustaveli State University, 6010 Batumi, Georgia \\ ${ }^{2}$ Batumi State Maritime Academy, 6010 Batumi, Georgia
}

\begin{abstract}
Today, everything in the world is changing rapidly; businesses that ten years ago may not have existed at all now exist and bring with them a significant income. Change in almost every field has one key feature: it is digitalisation. There are innovations in payment methods as well; the most high-profile issue in recent years in this regard is the emergence of cryptocurrencies. Within a few years of its appearance, it has become popular not even locally but worldwide. The method of data processing and analysis, quantitative and qualitative research methods, statistical-economic analysis methods are mainly used when working on the paper. The research aims to identify the main directions of cryptocurrency development in globalisation threats and challenges. Most cryptocurrencies are built on blockchain technology. The technology of the future is designed to securely store information, expedite transactions, reduce international transaction costs, replace cb-money with e-money and eliminate intermediary circles. Keywords: Money, Digital Currency, Cryptocurrency Market, Energy Deficit.
\end{abstract}

\section{Introduction}

What is cryptocurrency? - Nowadays, many people are looking for the answer to this question. However, before answering this, let us ask a more straightforward question: What is money? If you convince those around you, money can become anything, an object, or even an idea without a physical body. Money can be anything that can perform the function of money.

As a unit of trade and exchange, money has existed since ancient times, but many things have changed since the development of the economic process and the emergence of new ways of communication. The last point of these changes was the emergence of cryptocurrency, which, among other things, we must "blame" for technological progress.

The idea of creating e-money appeared years ago, but the first successful embodiment of this idea was Bitcoin. For many, this industry is associated with financial speculation, while others see the future of economic and financial relationships only in the digital world.

However, what is cryptocurrency? It is a digital currency that uses any transaction to record and store in a decentralised system known as a blockchain. Any information executed in a cryptocurrency in a blockchain is constantly updated, and it becomes

\footnotetext{
${ }^{*}$ Corresponding author: george.abuselidze@gmail.com
} 
impossible to falsify it. In order for the transaction to get into the blockchain, miners are needed.

The working principle of the miners is simple: they load new information into the block, and in return generate cryptocurrency, which can be considered as a reward for the work done. However, no matter how we delve into the details, the major revolutionary step in shaping the crypto world is integrating this level of money into the digital world, thus creating a whole new, decentralised financial reality that has yet to unleash its full potential [1].

A clear example of the new financial reality is the financial exchanges where cryptocurrency trading takes place daily. While there are still no outlines of how this area can be regulated at the legislative level, the fact is that the number of people expressing a desire to buy and trade cryptocurrency is growing daily.

Technological progress dramatically simplifies this process, which is why we have to put up with the reality we have encountered so quickly. It is impossible to ignore this reality, and we must find ways to adapt because when it all comes to the surface and touches every detail of our daily lives, then it may be too late. Therefore, we must keep pace with technological progress and use it to our advantage - to create a new, future reality $[2]$.

\section{Literature Review}

The paper is based on the theory of analysis and synthesis of concrete examples of international and Georgian experiences. Key issues are resolved on the basis of control and functioning relationships.

We can mainly highlight the works of the following authors: A. Bailey (2019), E. Bouri, S.J.H. Shahzad and D. Roubaud (2019), C. Brenig and G. Müller (2015), D. L. K. Chuen, L. Guo and Y. Wang (2017), A. E. Bahrawy, L. Alessandretti, A. Kandler, R. PastorSatorras and A. Baronchelli (2017), G. Hileman and M. Rauchs (2017), M. Iwamura, Y. Kitamura, T. Matsumoto and K. Saito (2019), Y. Liu and A. Tsyvinski (2021), U. A. K. Rogoff (2021), E. Tukhiashvili (2021), et al. [2-13]. However, despite the multifaceted discussion of the problem of cryptocurrency management (especially in conditions of uncertainty), it has been improperly studied and researched in the international literature and scientific publications. Bailey's paper analyses that one of the reasons why Bitcoin is among the top ten cryptocurrencies is that it is the oldest it has the largest community of developers and investors, which contributes to its further growth [2]. Authors showed that Most of the restricted prove on the exponential cost spikes (i.e. cost explosivity) within the cryptocurrency showcase considers the case of Bitcoin, even though other cryptocurrencies have slowly dissolved Bitcoin's dominance [3]. Against the background of global processes, authors determine the mechanism of functioning of the international currency market in the wake of its historical development [6, 14-17]. The authors discuss the essence and features of cryptocurrency, modern types of electronic money and blockchain technology, central bank regulation mechanisms, and the e-wallet and its characteristics, dynamics of cryptocurrency types (especially bitcoin regulation) and cryptocurrencies [8, $18]$.

According to the Authors, If not for the e-currency market, which would link economic entities in Georgia with foreign markets, entities in Georgia would have little chance of engaging in international currency trading. Through the electronic currency market, corporations and citizens of Georgia can acquire the necessary knowledge and experience, to be constantly aware of the current processes in the world currency market. At the end of the paper, based on the grouping of facts, combining them with common characteristics and their analysis, the main conclusions and recommendations are presented $[19,20]$. 


\section{Results and Discussion}

\subsection{Money in the Past, Present and Future}

Everything may be utilised as money if people agree and the right purpose is assigned to it. Money must fulfil multiple requirements: it must be a payment method, a means of collecting/storing value, a means of accounting, and it must be easy to use.

Money has existed for a long time as the equivalent of universal interchange, and the notion of economic interactions has led to its progressive evolution. Since the dawn of time, people have agreed that to carry out the trade process with one another, something universal, a standard that could be swapped for anything, was required [4].

The global equivalent unit was formed and evolved in this way. With the increasing degree of growth in society, this unit has been continually modifying at different periods of human evolution. Wheat, products, gold coins, currencies, and even cryptocurrency were all used at various eras. Cryptocurrency is the most recent technical advancement in the field of money.

There are over 5,000 cryptocurrencies in circulation throughout the world. Among them, Bitcoin ranks first (with a capitalisation of more than $\$ 1$ trillion). Also in the top ten are Cryptocurrencies by Market Capitalisation: Etherium, Binance Coin, Cardano, Tether, XRP, Solana, Polkadot, USD Coin and Dogecoin (Table 1).

Table 1. Top Cryptocurrencies by Market Capitalisation and Current Price, (29.10.2021)

[21]

\begin{tabular}{|c|c|c|c|}
\hline № & Coin Name & Market Capitalisation & Current Price \\
\hline $\mathbf{1}$ & Bitcoin & 1.15 trillion & 60829.88 \\
\hline $\mathbf{2}$ & Etherium & 447.41 billion & 3792.73 \\
\hline $\mathbf{3}$ & Binance Coin & 78.22 billion & 465.19 \\
\hline $\mathbf{4}$ & Cardano & 70.7 billion & 2.15 \\
\hline $\mathbf{5}$ & Tether & 69.03 billion & 0.99993 \\
\hline $\mathbf{6}$ & XRP & 52.47 billion & 1.12 \\
\hline $\mathbf{7}$ & Solana & 47.95 billion & 159.62 \\
\hline $\mathbf{8}$ & Polkadot & 40.92 billion & 41.43 \\
\hline $\mathbf{9}$ & USD Coin & 32.75 billion & 0.99987 \\
\hline $\mathbf{1 0}$ & Dogecoin & 31.08 billion & 0.24 \\
\hline
\end{tabular}

Cryptocurrencies have a long history dating back to the creation of Bitcoin in 2008 . Many attempts to establish worldwide electronic money existed before Bitcoin, but none were successful. Cryptocurrency appears to be conveyed by a mere arrangement of numbers and has no materiality. However, the situation is not so straightforward. Behind these transactions, in the case of Bitcoin, is a database - blockchain.

A blockchain may be compared to a decentralised database in which information is kept on several computers rather than a single control centre. Instead of a single control centre, data is disseminated among a number of computers that act as nodes. The copies on all of these computers (nodes) are identical. The nodes work precisely as the Bitcoin algorithm specifies. Trying to fabricate information here is impossible and meaningless since, despite the theoretical possibility of fabricating information on one node, information on other nodes throughout the network remains intact [6].

So the nodes are continually broadcasting to one other, communicating to each other, spreading information, and warning each other of changes in the blockchain. This data is synced between them regularly.

Let us take a look at what a blockchain. Each new block is appended to the preceding block using cryptographic procedures, making it impossible to modify the information 
stored in the prior block. This is how a lengthy chain of linked blocks is created, which is why this database is known as a blockchain. Miners, who are in charge of the system's functioning, records information or store it in transaction blocks.

The job of miners in the Bitcoin network is to validate all transactions. They get compensated in the form of newly minted bitcoins from the system in exchange for their efforts.

The whole bitcoin design is based on an incentive structure that encourages all players to be honest, rather than rewarding players (system participants) for dishonest behaviour, for which they would be condemned and held responsible.

Cryptocurrencies' whole design is built on the most challenging encryption and higher mathematics, with game theory utilised to develop successful consensus models. Throughout the bitcoin system, the structure is impartial and balanced, the game's rules are known to everyone and defined in the protocol from the start, nobody really trusts anyone at all, and good conduct is valued while negative behaviour is condemned.

Bitcoin is a game-changing invention, a technology that radically transforms the way people think about money. In our opinion, Satoshi Nakamoto (creator of Bitcoin) is a modern Prometheus who set fire to humans in his time. Satoshi lay the groundwork for a new era of decentralisation by demonstrating the paradigm of unregulated currency.

Organisations, enterprises, and people can no longer ignore the need for digital attitudes and technology transformation. Businesses all across the globe are preparing their existing processes, competencies, models, and transactions for digital transformation. This transformation has resulted in the digitisation of financial institutions and operations. Bitcoin, likewise, is a product of this technological advancement.

The public's interest in the perceived worth of this cryptocurrency has surged as a result of its rapid rise in value. As a result, many speculators and gamblers have hurried to invest in this currency in the hopes of achieving enormous future profits. This has not only acted as a key spur for the currency's perceived worth to grow, but it has also made the currency exceedingly unpredictable. Some traders consider bitcoins to be an appealing investment instrument because of the unique attributes of keeping the digital trace of individuals who deal in bitcoin anonymous and that it is not controlled by any governing body or firm.

On January 1, 2016, the sustainable growth of Bitcoin began. It started 2016 with $\$ 433$ and ended with \$ 959 - a 121\% increase in value in 12 months. From January to December 2017, extra attention, the introduction of new cryptocurrencies, and media coverage increased the value of the cryptocurrency from January $(\$ 921)$ to December $(\$ 13,062)$. This record margin was ultimately unstable, and Bitcoin fell victim to its routine variability, which steadily eroded its previous gains. However, this only lasted until 2020. When economic activity slowed due to global isolation during the initial outbreak of the pandemic, the price of Bitcoin began to rise again (Figure 1).

Cryptocurrency started 2020 with $\$ 7,200$. The pandemic and the policies pursued by the governments of various states have sparked investor fears about the global economy and accelerated the rise in the price of Bitcoin. At the end of November, Bitcoin was trading for $\$ 18,115$. In December 2020, the price of Bitcoin reached $\$ 29,000$, which means that from the beginning of 2020 to the end of the year, its price increased by $302 \%$.

Bitcoin (BTC) in 2021 (from January to October 2021) has already grown by $100 \%$. As early as February 21, 2021, Bitcoin (BTC) reached its highest point - \$58,332. All this means that the most expensive e-money has grown by $100 \%$ in just two months since the beginning of 2021. At the beginning of January, the price of one Bitcoin (BTC) was \$ 33,063 , and as of October 2021, the price of one Bitcoin (BTC) is already \$ 59,056 [22]. 


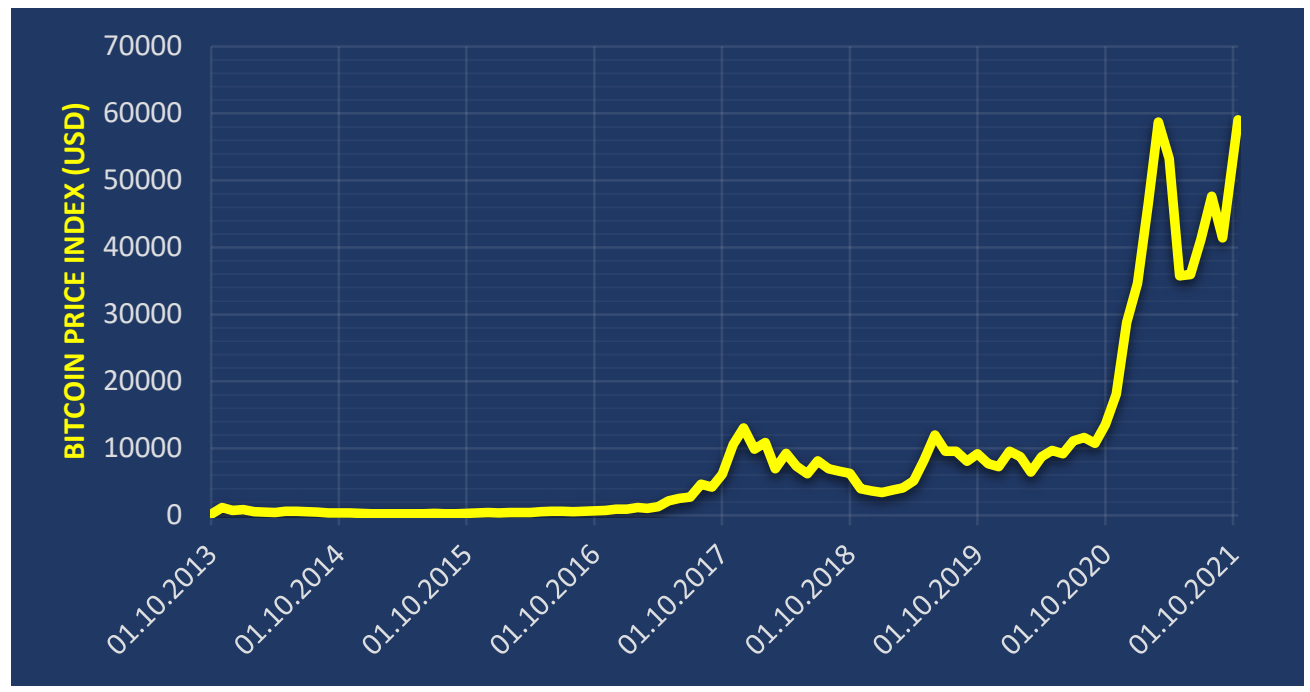

Fig. 1. Bitcoin Price Index in Dynamics, 2013-2021*

Source: Compiled by the authors based on data from [22]

At the same time, Elon Musk's company "Tesla" had a significant impact on the price of Bitcoin, after, on February 8, they invested a large part of the company's budget - $\$ 1.5$ billion, in Bitcoin (BTC). It was announced that it would be possible to buy Tesla cars in cryptocurrency.

In this way, Tesla diversified its surplus assets in order to maximise profits. A few days before the information was released, Musk even posted \#Bitcoin in his Twitter account description, indicating that he took cryptocurrency seriously. Analysts say Tesla's move will bring significant changes and shifts to the crypto world. At this point, the price of the cryptocurrency has risen dramatically.

It is also noteworthy that such a move from a company with so much influence was a bit unexpected, and it might give us a chain reaction. According to many experts, such a record rise in the price of Bitcoin (BTC) is due to the support for Bitcoin by the big companies that cryptocurrency has been receiving lately.

To buy Bitcoin, we first need to download the appropriate application (free of charge) and create a user that will allow you to get your account number. We must never forget the account number to complete the transaction, as our personal wallet is created with the account number. Also, bitcoin can be mined even if we do not complete any transactions we just help to create blockchains and get cryptocurrency in it.

Nowadays, in many countries, it is possible to exchange the received bitcoins into the currency of your choice through both banks and ATMs. It is also possible to use it as a medium of exchange without exchanging for other currencies, as all of these cryptocurrencies currently have exchange rates.

\subsection{The Main Challenges of Cryptocurrency Development in Georgia}

Georgia, a country in Eastern Europe, is known in the crypto-society for two reasons:

- The first is cryptocurrency mining (due to its relatively low electricity costs, as well as its favourable tax environment and solid technical scene, which provide significant incentives for miners).

- The second is the fact that the National Agency of Public Registry has been recording land ownership information on the Bitcoin blockchain since 2015, which is a significant 
tangible innovation in the public sector worldwide. This has been said and written about many times in the international press, which is good in itself and helps to position Georgia in a positive context.

In September 2018, the first international mining summit was held in the capital of Georgia - Tbilisi, where up to 1000 participants from different countries of the world gathered. Tbilisi has once again become the focus of the global crypto community.

Now mining is no longer so relevant because millions of people worldwide have decided to get rich in this simple way, buy a device and secure their network connection. Consequently, the production of cryptocurrencies has dropped significantly, and this activity has become less attractive. As for maintaining the image of innovation in the country, the initiatives of the Government of Georgia in connection with the 3rd generation blockchain - Cardano, are important in this direction. They announced cooperation with the Ministry of Education and Science of Georgia [11].

In another direction, the situation in Georgia is not so favourable. We do not have relevant regulations that will regulate the field. Georgia does not yet have the legislative clarity necessary for attracting foreign investors and developing the field. It is important to introduce appropriate regulatory norms in a timely manner. Estonia, for example, has managed to attract several billion in foreign investment simply because it has offered an appropriate friendly legal environment to investors (Estonia has so far issued up to 1,200 licenses for crypto e-wallets and trading platforms).

Most recently, an order of the Minister of Finance was issued in Georgia, which defines the issue of taxation of mining. However, there is still much to be clarified by the legislation. Unfortunately, an essential problem in Georgia is that Georgian banks do not show mercy to crypto companies; they do not serve them. Without banks, it is still impossible to produce full-fledged business processes and develop business [23].

The global pandemic has changed the structure of the economy. Consumer prices are rising catastrophically, the devaluation of the national currency continues, the countries are heavily dependent on imports, and there is no fundamental economic basis to stop these processes [24-27]. Over the last 2-3 years, the National Banks of many countries and international banks have been actively working on digital currency issues: conducting surveys, testing technical capabilities, and issuing digital currencies. One of the motivations for the release of digital currency is that if it is released properly, it will bring price stability to many sectors of the economy. Therefore, a stable digital currency for Georgia may be the most effective way out of this difficult situation.

It is the last year that cryptocurrency has decentralised financial resources concentrated in the hands of states. For example, if today the state's financial power is concentrated in its National Bank and it sets the rules of the game, the rapid development of cryptocurrency has brought about the fact that the state is losing influence in this area.

Consequently, in order to somehow stop this process and regain the reins of financial management, the central banks of many countries began to issue digital currency. By the way, small countries started it even earlier, five or six years ago, because they saw great investment potential in national cryptocurrencies [1].

Countries that did not have competitive advantages and additional economic strength, creating their own digital currency added investment attractiveness. An example of this is Malta, which has received more than $\$ 2$ billion in foreign direct investment in the six months since the national digital currency legislation adoption.

Therefore, if we look at the current processes in the world, the entire global tax system is moving to cryptocurrencies. Georgia cannot be an exception. 


\subsection{SWOT-Analysis of the Cryptocurrency Market: A Theoretical Review}

To recognise cryptocurrency as a means of payment worldwide, it is necessary to regulate its extraction, revenue and circulation processes, both in individual countries and around the world. At present, there is no common law in the world regarding the processes related to the regulation of cryptocurrency.

Proponents of digital currencies like to talk about the interest in virtual money of celebrities, sports and show business representatives; however, they stubbornly do not notice how much cryptocurrency has made life easier for hackers and extortionists. At the same time, anonymous cryptocurrencies have become an ideal tool for paying taxes, money laundering, organising terrorist attacks and other dangerous crimes.

The idea that cryptocurrency is a harmless way to accumulate is incredibly mimetic. Retailers typically make almost no use of virtual money due to its high transaction costs, but for anyone looking to avoid money laundering, money laundering, evading international sanctions, or committing many other crimes, they cannot find a better ally than cryptocurrency.

In order to better present the prospects and threats of cryptocurrency, we will try to present a SWOT analysis of the cryptocurrency market (Figure 2).

Sooner or later, governments will have to tighten their control over virtual money. Today, this process has begun, and as a rule, this should reduce the demand for cryptocurrency, but it still does not happen. So why is cryptocurrency expensive? The answer is given in part by economic theory, according to which giant soap bubbles appear on the market under conditions of zero interest rates. It is an asset that has virtually no value; however, so many large institutional investors have entered this market that politicians will find it very difficult to regulate cryptocurrencies [10].

In our opinion, the longer taking control of digital money takes time, the more difficult it will be to regulate cryptocurrency in the future. The fact is that much more international coordination is needed to control cryptocurrencies, at least in developed countries.

Bitcoin has become the driving force of the illegal global economy, and it will take decades for even the strongest and wealthiest countries to control it. The main and almost the only apparent advantage of virtual money is anonymity and uncontrollability. As soon as it falls within the framework of official regulation, the demand for it will decrease dramatically.

In addition, the development of the crypto industry requires huge amounts of electricity, which in all probability may lead to disruptions in the energy supply. It is a well-known fact that large cryptocurrency "farms" consume as much electricity as some cities. As a result, factories may slowly shut down, people may become unemployed, budgets may not be met, and costs may increase. Mass bankruptcy will be a matter of time.

In the event of the development of this scenario, humanity will have to deal with an invisible and, at the same time, a big problem - energy shortage. As a result, the entire burden of rising energy prices on the international market will affect the economy. Factories will stop, costs for farmers will increase, and almost all goods that require energy production will become significantly more expensive.

However, the crypto industry is also making progress in energy - making virtual money requires so much electricity that it will be possible to introduce new technologies in alternative energy in the world. 


\begin{tabular}{|c|c|}
\hline STRENGTHS & WEAKNESSES \\
\hline 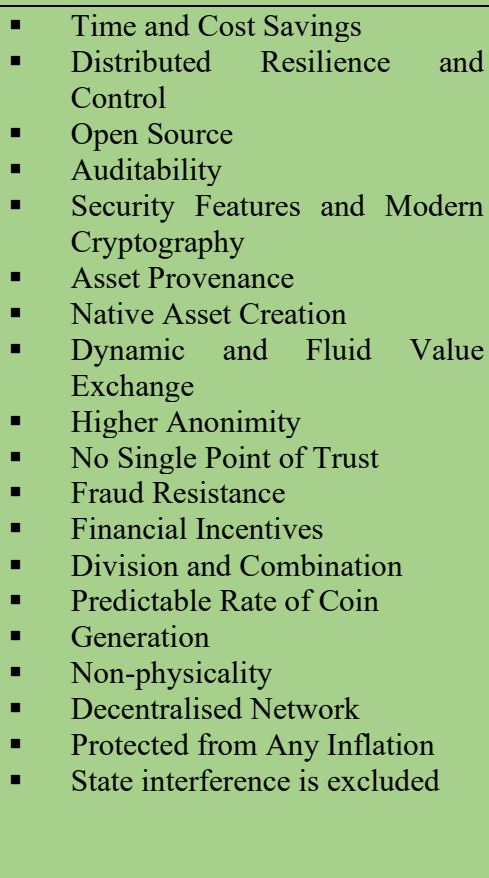 & $\begin{array}{l}\text { - } \text { Currency in Name Only } \\
\text { - } \quad \text { Lack of Ledger Interoperability } \\
\text { - } \text { Lack of Hardened/Tested Technology } \\
\text { Model } \\
\text { - Wallet and Key Management } \\
\text { Lack of Trust in New Technology Suppliers } \\
\text { - Lack of Skilled Human Resources } \\
\text { Immature Scalability } \\
\text { - Skills Scarcity and Cost } \\
\text { Customer Unfamiliarity and Poor User } \\
\text { Experience } \\
\text { Braking anonymity through transaction history } \\
\text { The deflation and hording problem } \\
\text { Lost Bitcoins } \\
\text { The transaction is not insured (usually you will } \\
\text { not be able to get back the currency transferred } \\
\text { after the transaction and no one will ever be able } \\
\text { to return it to you) } \\
\text { There is always a security risk (since e-wallets } \\
\text { are one of the targets of hacker attacks. In } \\
\text { addition, there is no state or international tool to } \\
\text { protect cryptocurrency deposits) }\end{array}$ \\
\hline OPPORTUNITIES & THREATS \\
\hline $\begin{array}{ll} & \text { Active Software Development } \\
\text { Community } \\
\text { Business Process Acceleration } \\
\text { and Efficiency } \\
\text { - } \\
\text { Dependable Savings } \\
\text { Reduced Transaction Costs } \\
\text { (Decrease in Transfer Fees) } \\
\text { - Reduced Fraud } \\
\text { - Reduced Systemic Risk } \\
\text { - } \text { Monetary Democratisation } \\
\text { New Business-model } \\
\text { Enablement } \\
\text { Application Rationalisation and } \\
\text { Redundancy } \\
\text { - } \text { Gig Economy } \\
\text { Libra as Onramp to Widespread } \\
\text { Adoption } \\
\text { Formation of Alternative Energy } \\
\text { Sources }\end{array}$ & 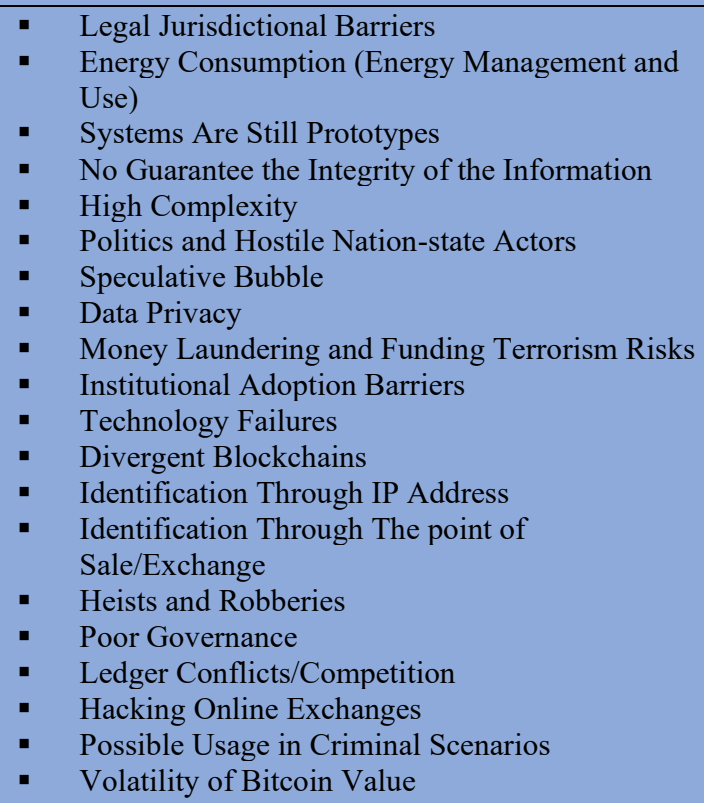 \\
\hline
\end{tabular}

Fig. 2. SWOT Analysis of Cryptocurrency

Source: Compiled by the authors 


\section{Conclusion}

In recent years, the facts of hacking trading platforms show that consumers should keep their cryptocurrencies not on trading exchanges but in a special crypto-wallet, the private key of which they will control themselves.

However, Bitcoin can be useful for many people. We can use it in any country, as it is an international currency. Blockchain is secure, and it allows us to make sure our money is moving/coming from the right person. Bitcoin recipients will not have to pay for transactions; Bitcoin has excellent support.

Sure, it has some downsides, but some of them happen because Bitcoin is a new, innovative product with high risks. However, as time goes on, the more the risks of uncertainty decrease and the less they pose a problem. All this will help Bitcoin gain more users, and if everyone uses Bitcoin, it can change the official currencies.

Given all the above, it should be emphasised that no one opposes blockchain technology, which is the basis of cryptocurrencies, and it has a huge potential for improving people's lives.

\section{References}

1. G. Zoidze, Three Seas Economic Journal 2(3), 1-7 (2021). doi:10.30525/26615150/2021-3-1

2. A. Bailey, The Future of Cryptocurrencies. KuppingerCole Report, ADVISORY NOTE (2019)

3. E. Bouri, S. J. H. Shahzad, D. Roubaud, Finance Research Letters 29, 178-183 (2019)

4. C. Brenig, G. Müller, Economic analysis of cryptocurrency backed money laundering. (2015)

5. D. L. K. Chuen, L. Guo, Y. Wang, The Journal of Alternative Investments 20(3), 16-40 (2017)

6. A. ElBahrawy, L. Alessandretti, A. Kandler, R. Pastor-Satorras, A. Baronchelli, Royal Society open science 4(11), 170623 (2017)

7. G. Hileman, M. Rauchs, Cambridge Centre for Alternative Finance 33, 33-113 (2017)

8. M. Iwamura, Y. Kitamura, T. Matsumoto, K. Saito, Hitotsubashi Journal of Economics, 41-60 (2019)

9. Y. Liu, A. Tsyvinski, The Review of Financial Studies 34(6), 2689-2727 (2021)

10. K. Rogoff, A Curse Worse than Cash. The World's Opinion Page: Project Syndicate. (2021)

11. E. Tukhiashvili, Digital Georgian Lari - What will the cryptocurrency of the National Bank bring us? Kviris Palitra. (2021)

12. G. M. Caporale, L. Gil-Alana, A. Plastun, Research in International Business and Finance 46, 141-148 (2018)

13. Q. Ji, E. Bouri, C.K.M. Lau, D. Roubaud, International Review of Financial Analysis 63, 257-272 (2019)

14. G. Abuselidze, Academy of Strategic Management Journal 18(4), 1-10 (2019)

15. G. Abuselidze, N. Reznik, A. Slobodianyk, V. Prokhorova, Global Financial Derivatives Market Development and Trading on the Example of Ukraine, in Proceedings of the SHS Web of Conferences 74, 05001 (2020).

doi:10.1051/shsconf/20207405001 
16. G. Abuselidze, European Journal of Sustainable Development 8(1), 53-68 (2019). doi:10.14207/ejsd.2019.v8n1p53

17. G. Abuselidze, L. Beridze, The Role of Alternative Investments in the Development of Capital Markets in Terms of the Transformation of Georgia with the EU, in Proceedings of the 4th International Conference on European Integration, 29-40 (2018)

18. Z. Ji, G. Abuselidze, V. Lymar, Currency Internationalisation and Reforms in the Architecture of the Monetary System: the case of Digital Yuan. Studies of Applied Economics. (to be published)

19. D. Katamadze, G. Abuselidze, G. Katamadze, A. Slobodianyk, Economics and Management 18(1), 19-32 (2021)

20. G. Zoidze, G. Abuselidze, Entrepreneurship 9(2), 33-46 (2021). doi:10.37708/ep.swu.v9i2.3

21. CryptoSlate, Coin Rankings. (2021). Available at: https:/cryptoslate.com/coins/

22. Statista, Bitcoin price from October 2013 to October 29, 2021 (in U.S. dollars). (2021). Available at: https://www.statista.com/statistics/326707/bitcoin-priceindex/

23. Business Media Georgia, Cryptocurrency - a new stage of finance. (2019)

24. G. Abuselidze, L. Mamaladze, Journal of Physics: Conference Series 1840, 012040 (2021). doi:10.1088/1742-6596/1840/1/012040

25. G. Abuselidze, A. Slobodianyk, E3S Web of Conferences, 210, 15016 (2020). doi:10.1051/e3sconf/202021015016

26. G. Abuselidze, The Influence of Covid-19 on the Public Debt Growth and Default Risk: A Fiscal Sustainability Analysis, in Proceedings of the International Scientific and Practical Conference on Sustainable Development of Regional Infrastructure - ISSDRI 2021, 151-159 (SciTePress, 2021). doi:10.5220/0010587501510159

27. G. Abuselidze, M. Sharabidze, MATEC Web of Conferences 342, 08003 (2021). doi:10.1051/matecconf/202134208003 